Original Research Paper

\title{
George (Gogu) Constantinescu
}

\author{
${ }^{1}$ Relly Victoria Virgil Petrescu, ${ }^{2}$ Raffaella Aversa, ${ }^{2}$ Antonio Apicella, \\ ${ }^{3}$ Samuel Kozaitis, ${ }^{4}$ Taher Abu-Lebdeh and ${ }^{1}$ Florian Ion Tiberiu Petrescu \\ ${ }^{1}$ ARoTMM-IFToMM, Bucharest Polytechnic University, Bucharest (CE), Romania \\ ${ }^{2}$ Advanced Material Lab, Department of Architecture and Industrial Design, \\ Second University of Naples, 81031 Aversa (CE) Italy \\ ${ }^{3}$ Florida Institute of Technology, USA \\ ${ }^{4}$ North Carolina A and T State University, USA
}

Article history

Received: 25-11-2017

Revised: 27-11-2017

Accepted: 4-12-2017

Corresponding Author: Florian Ion Tiberiu Petrescu ARoTMM-IFToMM, Bucharest Polytechnic University, Bucharest (CE), Romania Email: scipub02@gmail.com

\begin{abstract}
George (Gogu) Constantinescu (October 4, 1891 - December 11, 1965) was a Romanian scientist and engineer, often considered to be one of the most important Romanian engineers. He was responsible for creating a new field of mechanics, called "sonicity," which describes the transmission of energy through vibrations in fluid or solid bodies. He applied the new theory to numerous inventions: sonic, sonic hammer, sonic pomp and others. Among other achievements, there is also a pulling device among the propeller blades regardless of its speed and the first automatic gearshift. He has actively participated in the construction of English aircraft, the Bristol type, while he lived in England. He was the first to use reinforced concrete in the construction of buildings in Romania (among the buildings he built, we can mention: the Patriarchal Palace, the Athénée Palace Hotel and the Great Mosque in Constanta). Gogu Constantinescu was one of those brilliant minds, whose ideas have long outstripped his physical existence, but which today preserves its topicality, surprising by its accuracy, inventiveness and applicability. Gogu Constantinescu's account includes over 317 patents patented in the USA, Denmark, Switzerland, Austria, Germany, Great Britain, France, Romania, etc., as well as others that have never been published. A small calculation shows that since the first invention (1907), until the date of transition to eternity (1965), on average every 4 months a patent was made and if we count only the most prolific years, it results in invention per month. We can say that what Tesla did in electronics, Constantinescu succeeded in mechanics. If Nicolae Tesla invented and transmitted electromagnetic waves (electromagnetic oscillations) through the atmosphere, George Constantinescu invented mechanical sonic oscillations with which he transmitted sonic waves only through continuous media (tubes or pipes, water, oil, various liquids, air, gas, or full bars). Both transmit the waves (produced by oscillations), as well as the energy and power included in these waves, thus managing to transmit energy and power at small, medium, large, even very large distances, controlling and controlling the phenomena and processes from a distance or a large distance.
\end{abstract}

Keywords: George (Gogu) Constantinescu, A Romanian Scientist and Engineer, Sonicity, Transmission of Energy Through Vibrations, Sonic Motors, Sonic Pump, Sonic Hammer

\section{Introduction}

George (Gogu) Constantinescu (October 4, 1891 December 11, 1965; Fig. 1) was a Romanian scientist and engineer, often considered to be one of the most important Romanian engineers (Petrescu, 2016).

He was responsible for creating a new field of mechanics, called "sonicity," which describes the 
transmission of energy through vibrations in fluid or solid bodies. He applied the new theory to numerous inventions: sonic, sonic hammer, sonic pomp and others. Among other achievements, there is also a pulling device among the propeller blades regardless of its speed and the first automatic gearshift. He has actively participated in the construction of English aircraft, the Bristol type, while he lived in England.

$\mathrm{He}$ was the first to use reinforced concrete in the construction of buildings in Romania (among the buildings he built, we can mention: the Patriarchal Palace, the Athénée Palace Hotel, Fig. 2 and the Great Mosque in Constanta).

Gogu Constantinescu was one of those brilliant minds, whose ideas have long outstripped his physical existence, but which today preserves its topicality, surprising by its accuracy, inventiveness and applicability.

Gogu Constantinescu's account includes over 317 patents patented in the USA, Denmark, Switzerland, Austria, Germany, Great Britain, France, Romania, etc., as well as others that have never been published. A small calculation shows that since the first invention (1907), until the date of transition to eternity (1965), on average every 4 months a patent was made and if we count only the most prolific years, it results in invention per month.

We can say that what Tesla did in electronics, Constantinescu succeeded in mechanics.

If Nicolae Tesla invented and transmitted electromagnetic waves (electromagnetic oscillations) through the atmosphere, George Constantinescu invented mechanical sonic oscillations with which he transmitted sonic waves only through continuous media (tubes or pipes, water, oil, various liquids, air, gas, or full bars).

Both transmit the waves (produced by oscillations), as well as the energy and power included in these waves, thus managing to transmit energy and power at small, medium, large, even very large distances, controlling and controlling the phenomena and processes from a distance or a large distance.

The main difference between the two great engineers is how they managed to do this.

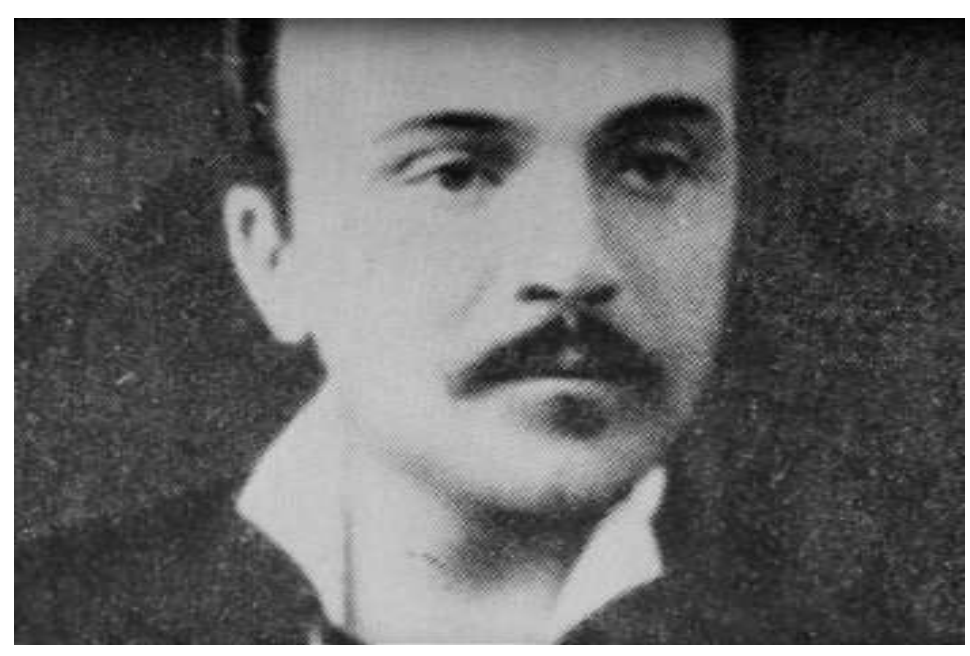

Fig. 1: George Constantinescu

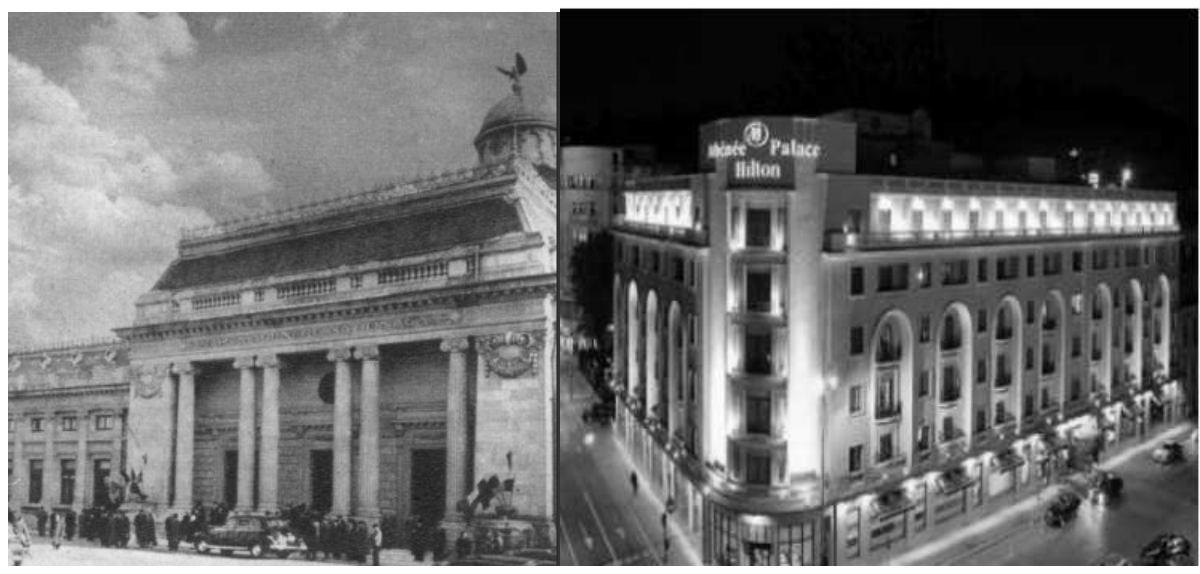

Fig. 2: The patriarchal palace, the Athénée palace hotel 
If Gogu Constantinescu transmitted power only through continuously closed environments, Nicolae Tesla began with DC cables, continued with the monophase, biphasic and polyphase alternating currents, switched to the transmission of energy through the air (over small distances) and then on large and very large distances, at first unconcentrated powers (dissipated energy) of the type of radio waves, to finally transmit energies concentrated through the electromagnetic waves.

George Constantinescu initially transmitted small and medium powers through sonic vibrations, so that he can then transmit large and very large energies (powers), concentrated, even at great distances. By comparing his achievements with those of classical mechanics and hydraulics, "Mr. Constantinescu's methods are a step forward," being simpler, more natural, more interesting, more useful, more capable.

If in the hydraulic system any system needs at least two pipes (one for the tour and the other for the return), in the sonicity always use a single pipe.

Hydraulics only use fluid pressure, generally obtained by pressure (weight), while sonic science produces, stores transmits, receives and uses only through sonic vibrations.

Many of Gogu Constantinescu's predictions have emerged and gone, many are being used today, or retreating interest. He has gained academic fame and professional honesty at home and abroad, built and taught others how to build, invented new engineering methods, which he has always materialized, making them useful to people but also to humanity.

The synchronization of machine gun firing with propeller blades was a local utility (in space and time), but through the results of its application it has essentially contributed to changing the fate of the war and therefore of mankind and the planet.

\section{Materials and Methods}

Some of its inventions, however, have a more general character in terms of their applicability (in space and time). If he was sometimes less rewarded for what he did (materially) than most inventors, suffering disappointments in his efforts to convince the industry and officials of the value of his ideas, engineer George Constantinescu leaves it following her an extremely solid, technically-scientific heritage.

The scientist and engineer Gogu Constantinescu was the one who developed and applied the Theory of Sonicity, a new science relating to the transmission of power through liquids, solids, or gases. But Gogu is still commemorated by the general public and pilots of the Air Service, as the man who invented the synchronized firing device for WWI planes (Petrescu, $2017 \mathrm{a}-\mathrm{q}$ ).

In this context, on March 29, 1920, the famous newspaper "The Times" publishes: "Vice Marshal Sir John Maitland presided over a lecture by Mr. Gogu
Constantinescu on Sonicity (transmitting power through vibrations), given at the Polytechnic, under the auspices of a series of lectures for professors of the Land of London Council. Sir John Maitland said that because of Mr. Constantinescu and the firing device he invented, we held the supremacy over the Germans in the air, as we did. "

Although Gogu Constantinescu's work is of inestimable value, it was not known enough, largely because of its secret nature, imposed by the mainly military uses and on the other hand, the few publications related to it. Thus, the first volume published in London in 1918, in a limited number of copies, was declared secret by the UK government because of the new weapon and war theory applications.

On the occasion of the 125 th anniversary of the birth of our illustrious compatriot, we tried to fill the information gap on his achievements by the appearance of three significant works: "Inventeurs of Genie, Gogu Constantinescu.", Mediamira Publishing House, ClujNapoca 2006, (600 pages) and "The Integrity of Inventions" (4 volumes, over 2000 pages), Performance Publishing House of the National Institute of Inventions, Iaşi 2006 (papers published with the support of the National Authority for Scientific Research).

Gogu Constantinescu's international recognition is attested by a painting published by the British magazine "The Graphic" in 1926, which presents illustrious scientific personalities of the time, starting with Einstein, Edison, Kelvin, Gogu Constantinescu (first on the turn of the second), Rutherford, Marie Curie, etc., Fig. 3; (Petrescu, 2016; Aversa et al., 2017 a-d; 2016a-d; Mirsayar et al., 2017; Petrescu and Petrescu, 2016a-c; 2013a-d; 2012a-d; 2011a-b; Petrescu, 2012a-c; 2009; Petrescu and Calautit, 2016a-b; Petrescu et al., 2016a-b).

The domains touched by Gogu Constantinescu's genius were very diverse, the practical achievements being impressive, of which we mention a small part:

Promoted the use of reinforced concrete. It was a tough task because the method had disastrous results elsewhere in Europe, such as the Celestial Globe Bridge at the 1900 Universal Paris Exhibition and the 1902 Basle Black Bear Hotel.

He built the first bridge of reinforced concrete with straight crossbars in Romania (1906), strengthened the cupola of the Parliament Palace (who suffered displacements and cracks), made the dome of the Mosque in Constanta, etc. (despite the opposition of his former professor, the great Anghel Saligny). These works continue to exist today.

He invented the asphalt.

He developed Theory of Sonicity (the method of transmitting power, by a pressure wave, using the liquid compressibility property).

He built the most advanced airplane timing system through the space left by the propellers' wings.

He materialized the first sonic cannon (Fig. 4). 


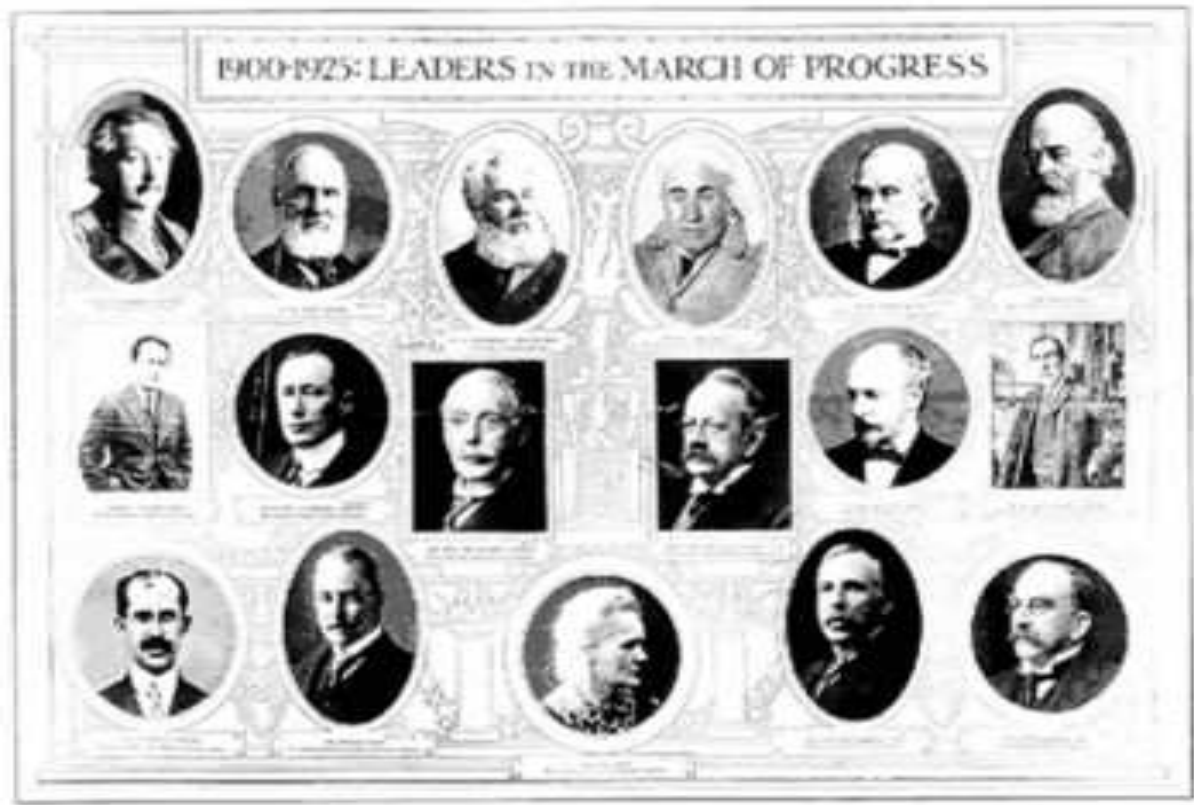

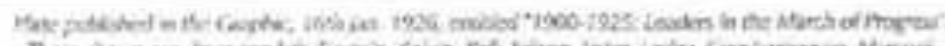

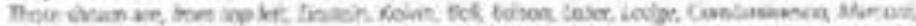

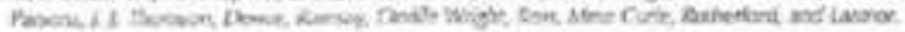

Fig. 3: Leaders in the March of Progress 1900-1925 (Constantinesco second row, far left)

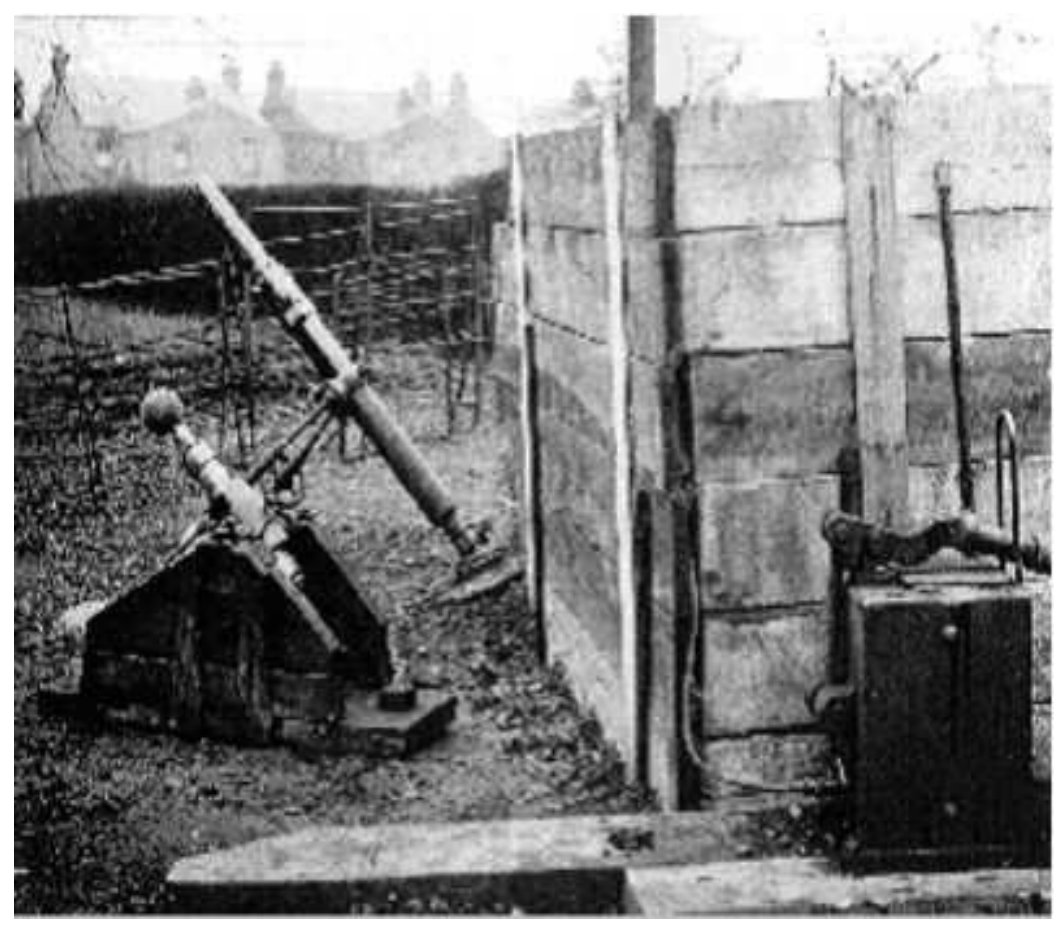

Fig. 4: The first sonic cannon

He designed and built the Gogu Constantinescu first automatic gearbox for cars and locomotives, without clutches and gears, based on the inertial effect of moving masses (Fig. 5).
He thought of the first Hydroblister that was materialized later in the 1970 s by the Russians.

He demonstrated the thermal effect of sonicity by making the first sonic heater. 


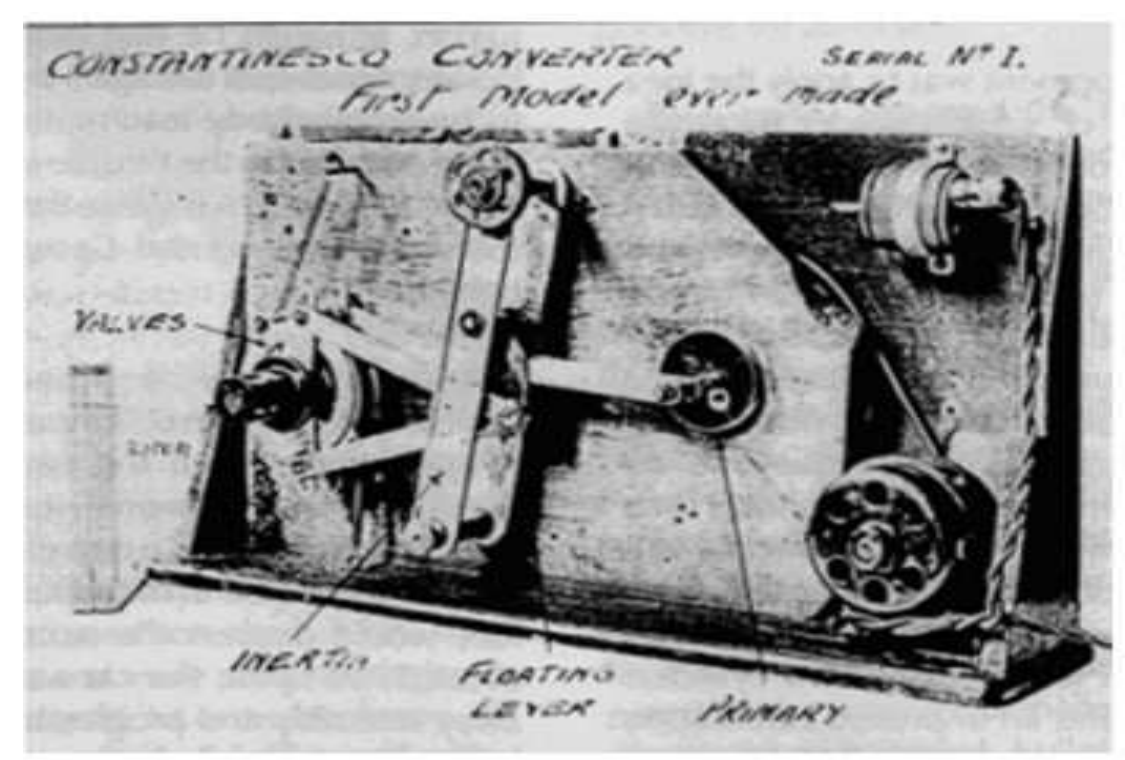

Fig. 5: First automatic gearbox for cars and locomotives

\section{Results}

Man George Constantinescu: He was born in Craiova on October 4, 1881, as a son of Gheorghe Constantinescu, a native of Ploiesti (brilliant professor of mathematics at Craiova high school) and of Anne Constantinescu, born Roy, of British-French origin, refugee Alsace due to the Franco-German War (1870), precisely on our land.

An early child, George Constantinescu, knew how to write and read before going to school. The high school makes it to Craiova, where he astonishes his teachers by his mathematical talent.

At home, he built all sorts of devices in his littleimprovised laboratory of physics and chemistry.

For his younger sister, refractory to the assimilation of his first knowledge in mathematics, he builds an ingenious computing machine that allows him to automatically obtain the results of arithmetic operations.

$\mathrm{He}$ had learned from his mother to play the piano with many talents. We can observe in this passion the origin of his engineering (later) concerns about the development of a theory of musical harmony that will lead him through a remarkable association of ideas in the construction of science "Sonicity", his basic invention.

The period of engineering studies at the National School of Bridges and Roads (today UPB) shows its special qualities, its courtesy and the ability to get an idea at the end.

Thus, although the professor of bridges, the famous Anghel Saligny, warned all students to avoid building reinforced concrete bridges, material that was then considered uncertain and even dangerous, G. Constantinescu projects in his diploma paper such a bridge, (which again reminds the student of the recalcitrant that such bridges and constructions will come to a halt), but GC He bravely replies that he will build them.

In the first six years after graduation, he has mastered his genius in the field of reinforced concrete, stating himself as one of the most active pioneers in this useful area.

He built the bridge on the road to Doftana (Fig. 6), the floors of the building of the Ministry of Public Works, the building of the Chamber of Commerce (now the Ministry of Commerce), the Palace of the Bursa (now the State Central Library), the park of the exhibition park (now Freedom Park) large bridges from Adjud, Răcăciuni, Roman and Dolhasca (on Siret), the consolidation of the Chamber of Deputies, the floor of the mosque tower in Constanța.

Due to the difficulties encountered during the first six years of engineering in all areas of work, but especially in the mechanical (sonic), he left for England in 1910, six years after graduating from the faculty.

In London, he manages to convince a capitalist to finance his inventions related to the power transmission through liquids.

This is how the first sonic laboratory in the world, in a shaft left on the banks of the Thames. In the short term, he gets concrete results, but a storm followed by an overflow of Thames floods the small lab, destroying all the equipment.

The capitalist is withdrawing from the deal.

He's trying to patent his inventions in the US, but he's hitting permanent refusals (he was charged with "what this crazy Romanian wants)". 


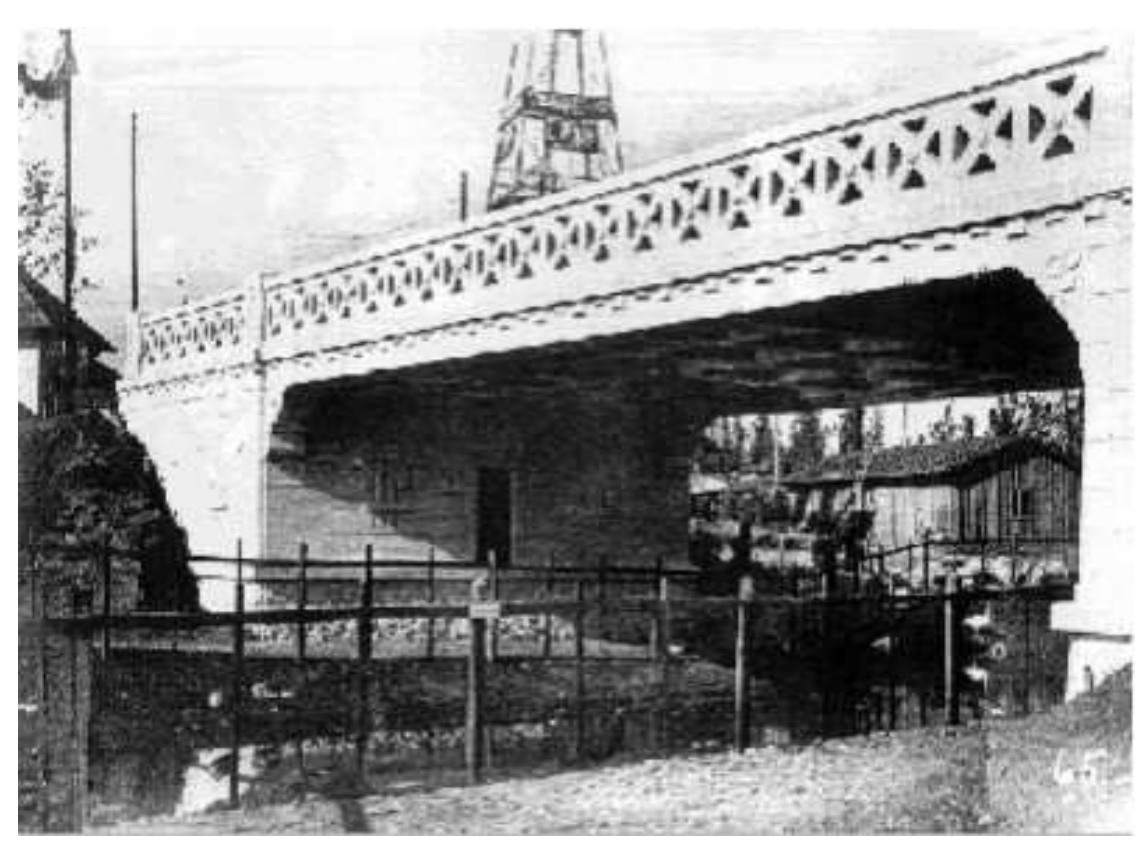

Fig. 6: The bridge on the road to Doftana

In the end, the process succeeds, but only after personalities from the English technical world have deposited for him and his theory vouchers, to the New York Patent Office.

On this occasion, he visits the United States in 1913 and, among other things, is invited by Edison, to a particular discussion of "musical harmony", consonant and dissonant sounds. G.C. he was very well prepared in the field, while Edison (who had just invented the Gramophone) fought in this field.

Returning to London he fails to impose his new science as he had hoped, but only indirectly thanks to the First World War.

In 1914, while the German army was airborne, with its much larger and better-prepared aviation, the English Admiralty alarmed by the thousands of lives slaughtered in its army took the initiative to set up a contest to find a solution to increase the power of fire, by pulling through the wings of the airplane's propeller, during the flight.

George Constantinescu is also present at this contest and with the modest technological and financial means, he realizes the first sonic synchronization and automatic firing device via the airplane propeller.

At the demonstration of this first model, the jury of the contest, made up of famous scholars including Lord Rayleigh and J.J. Thomson is basically amazed by the results of the young Romanian engineer's invention, its effectiveness, the accuracy of the shooting, the elegance and simplicity of the SONIC solution, an immediate solution, which gave the expected results, completely overturning the situation and bringing British aviation absolute supremacy (Fig. 7).
The British Government and the US Air Force have ordered the immediate delivery of 50000 such devices.

Now the English state provides the necessary funds for the rapid establishment of the laboratory "SONIC WORKS", which G.C. can now endow it with all the necessary technology and equipment (Fig. 8).

G.C. becomes famous overnight. The first results of his work are edited by British Admiralty in "The Theory of Sonics," in a small number of copies, who immediately received the "strictly secret" regime.

Thus, Coanda, who had built bimonthly planes for the British before and had already presented his reaction plane (a plane that could not be built at that time), was not as successful as that of engineer Gogu Constantinescu.

Among the visiting personalities in his laboratory was our great neurologist Gheorghe Marinescu, sent to England at that time on an official mission by the Romanian government. There is a special friendship between the two compatriots. In 1919 G.C. returns to the country invited by the Romanian Academy (at the recommendation of Professor Gheorghe Marinescu) to hold a conference on sonicity, a conference that had a great rhythm, attracting the attention of our engineering and financial circles. The SONICA Society is immediately established, with the purpose of capitalizing in the country of G.C. patents, already put into value in England and the USA. G.C. is recalled urgently in England. In our society, the company quickly goes bankrupt and remains owed. G.C. returns to the whole society the invested capital. His second attempt to put himself in the service of the country ended in a total failure. 


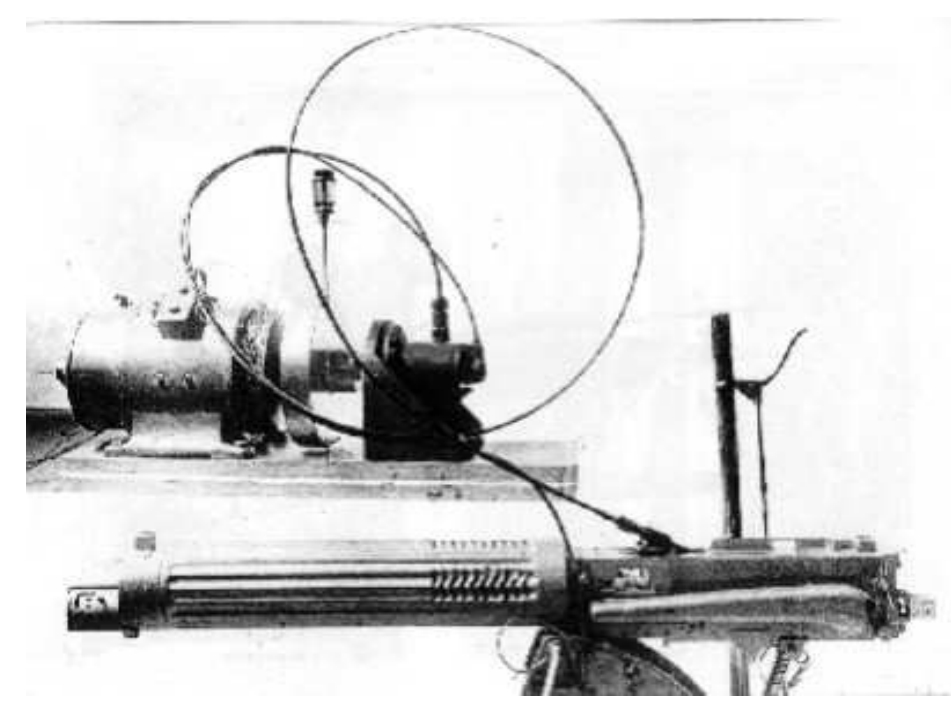

Fig. 7: The first sonic synchronization and automatic firing device via the airplane propeller

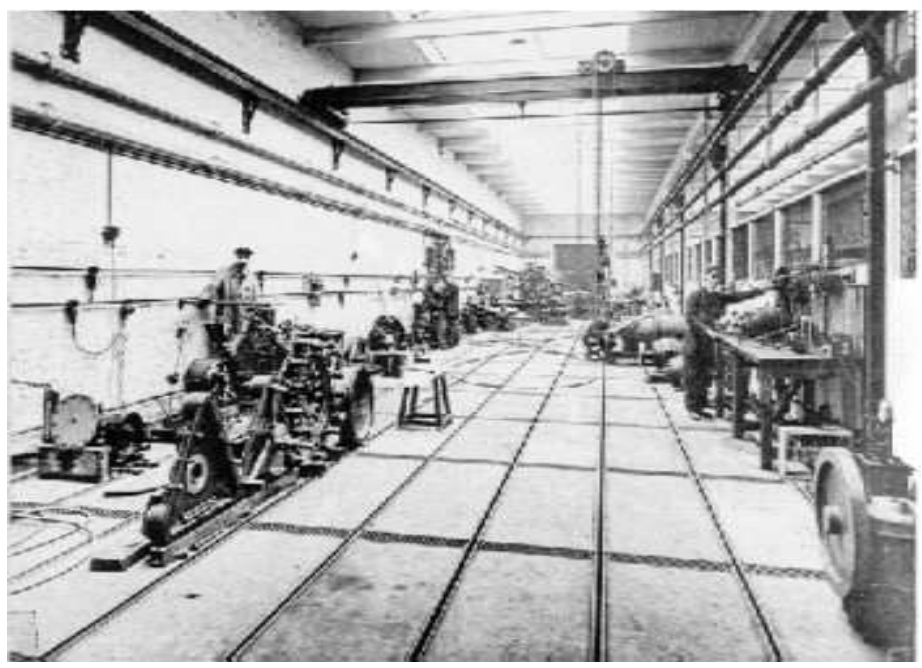

Fig. 8: The laboratory "SONIC WORKS

Now G.C. invented his famous torque converter. The first cars equipped with it are presented at the Wembley Industrial Exhibition in 1924 and then at the Paris Motor Show in 1926 (Fig. 9), the "The Feeling" invention, occasioned by the British magazine "The Graphic", from January 10, 1926, in the article "Leaders in the March of Progress", the figures of 17 great inventors and scientists from 1900 to 1925 are shown (Among them, alongside Albert Einstein, Guglielmo Marconi, Lord Rayleigh, Thomas Edison, Marie Curie and George Constantinescu).

In 1933, G.C. is making a new attempt to build in the country, concluding a contract with the Malaxa Plant for the application of G.C. to locomotives and motorcars manufactured here.

The first auto motor was tested on the BucharestOltenita line and it did very well, but it was not adopted by
Malaxa, given the pressures exerted by foreign firms on the governors and Romanian political leaders at that time for the introduction of a model foreign manufacturing (Fig. 10).

G.C. tells how the discredit and injury caused by the motor that he himself was driving through the derailing that he avoided at the last moment suddenly brakes after he noticed a crossing on the railroad.

Disgusted by the morals of our politicians G.C. returns definitively to England; he made only two short visits to the country at the invitation of the Romanian Academy in 1961 (when he was celebrated for his 80 years and received the high distinction of "Doctor Honoris Causa" of the Polytechnic University of Bucharest) and in 1963 (when he visits the installation sonic drilling in Ploiesti).

After one year he is extinguished (at the age of 83) in his villa in ENGLAND, on the shores of Lake Coniston, where he is buried. 


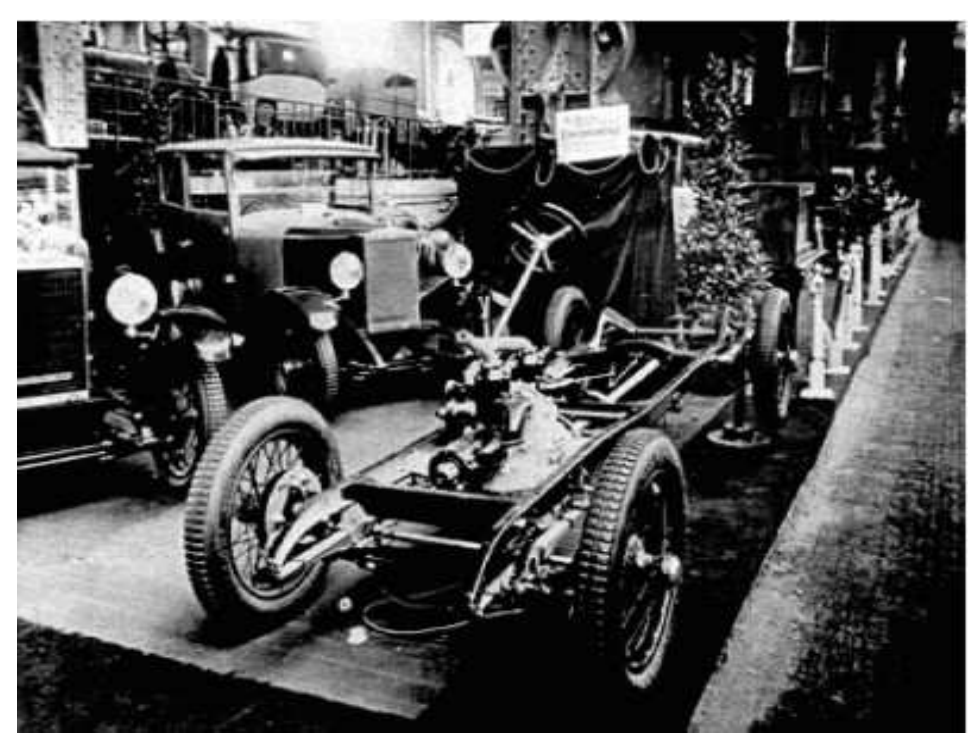

Fig. 9: The first GG's cars

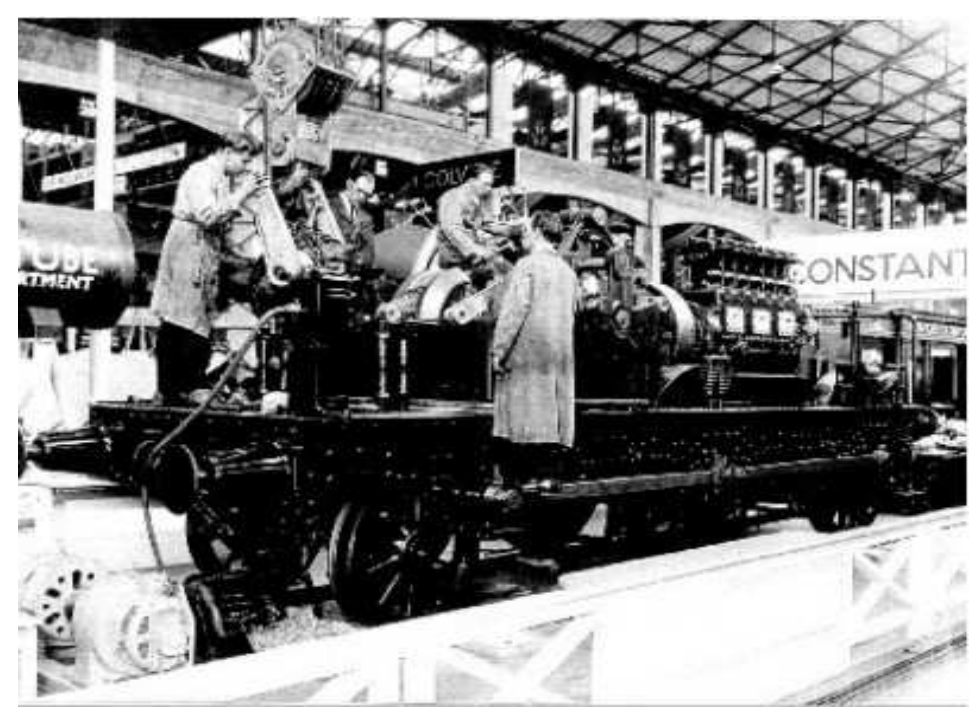

Fig. 10: The first auto motor was tested on the Bucharest-Oltenita line by GG

\section{Discussion}

In England, he has worked on all sorts of inventions, patents, innovations.

He developed several methods of deep-sea sonic drilling, methods that were partially implemented in the country.

He has improved the sonic injection of the injection pumps on the diesel engines. In the picture, you can see a sonic boom for improving and adjusting the injection of cars (Fig. 11).

He invented and built a sonic sound generator. It has a very high power, high intensity, low consumption, high fidelity, with very good acoustics and can be used as a siren for alarm (Fig. 12).
He built all kinds of sonic guns, with silent firing (without fire or gunpowder), with very small kickbacks, which pulled with great power at great distances, with high precision, without making the smallest noise, without fire or smoke without vibration. So he perfected his oldest silent shooting methods, with large caliber sonic guns. Its basic method was the storage of sonic energy in a resistant metallic cylinder (cylinder) by compressing (compressing) a liquid. The sonic pressure of the fluid gradually increased, but on the basis of sonic waves received up to the desired level (required), as in a sonic capacitor. The release of the sonic gun shell (pushed by the compressed sonic liquid) was made by opening the stopper (s) at the desired time. Everything was produced in total silence, without fuels, without fire and smoke, without explosions, as I showed without noise and vibration (Fig. 13). 


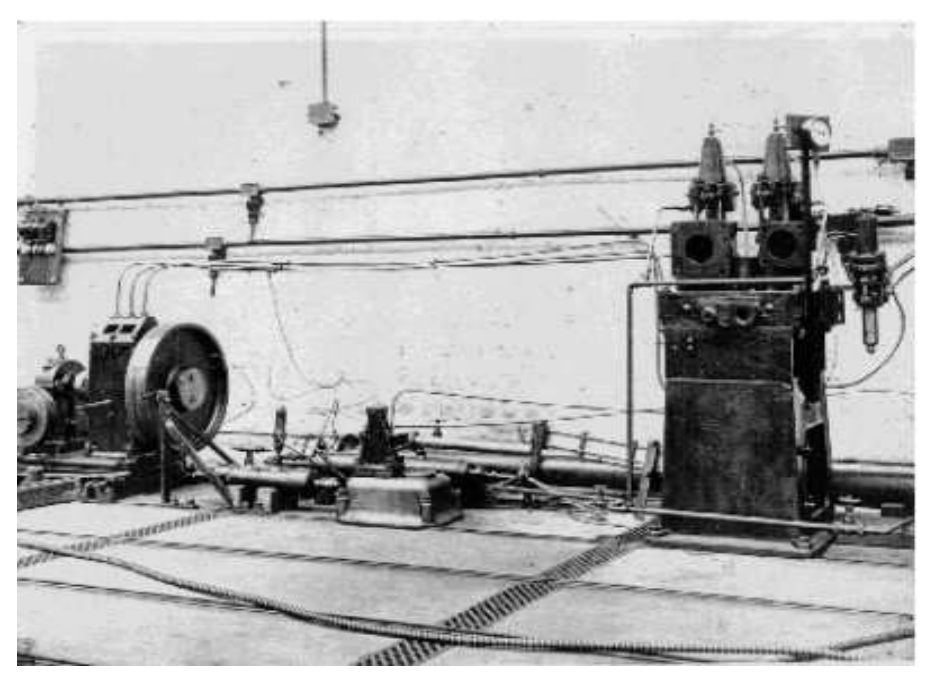

Fig. 11: The sonic injection of the injection pumps on the diesel engines

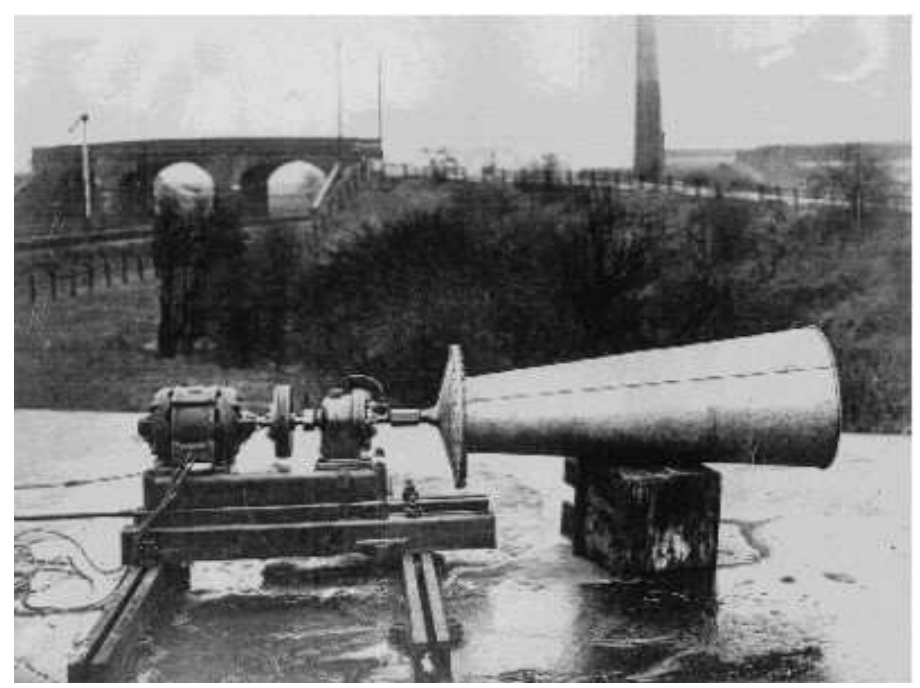

Fig. 12: A sonic sound generator

He invented and built the sonic hammer (sonic punch) much more powerful and performing than the pneumatic hammer, not to mention the much lower noise level (Fig. 14).

He invented and built the sonic transmission of marine vessels, which has the advantage of transmitting power through a single duct, without requiring two pipes for an installation (as required by hydraulic installations). In the Fig. 15, there is shown a special four-phase (four-phase) sonic transmission installation (such a system would require eight pipes hydraulically).

Generators and Sonic Engines are built in a very wide range. They are generally synchronous or asynchronous. It is further classified as monophasic or polyphase. Rotary sonic motors are convenient for power distribution for any kind of industrial purposes. Several independent sonic motors can be coupled and unplugged to (from) a sonic feed line that can be a single pipe (single-phase system) or multiple (polyphase) pipes.

Synchronous sonic motors are unique in the field of mechanics through that feature of maintaining a rigorous synchronicity between them and the generator. Classical reducer systems can be replaced by compact sonic motors, interconnected by small diameter pipes through which the sonic energy is transported.

They can be used in industrial halls, on various machines such as locomotives, automobiles, agricultural machinery (combines, seeders), tractors, trucks, buses, boats, catamarans, hovercrafts, submarines, boats, etc.

Asynchronous sonic motors (Fig. 16 shows a single, three-phase version) are convenient for applications where the loads are very variable (for locomotives, tractors, boats, excavators, cranes, etc). 


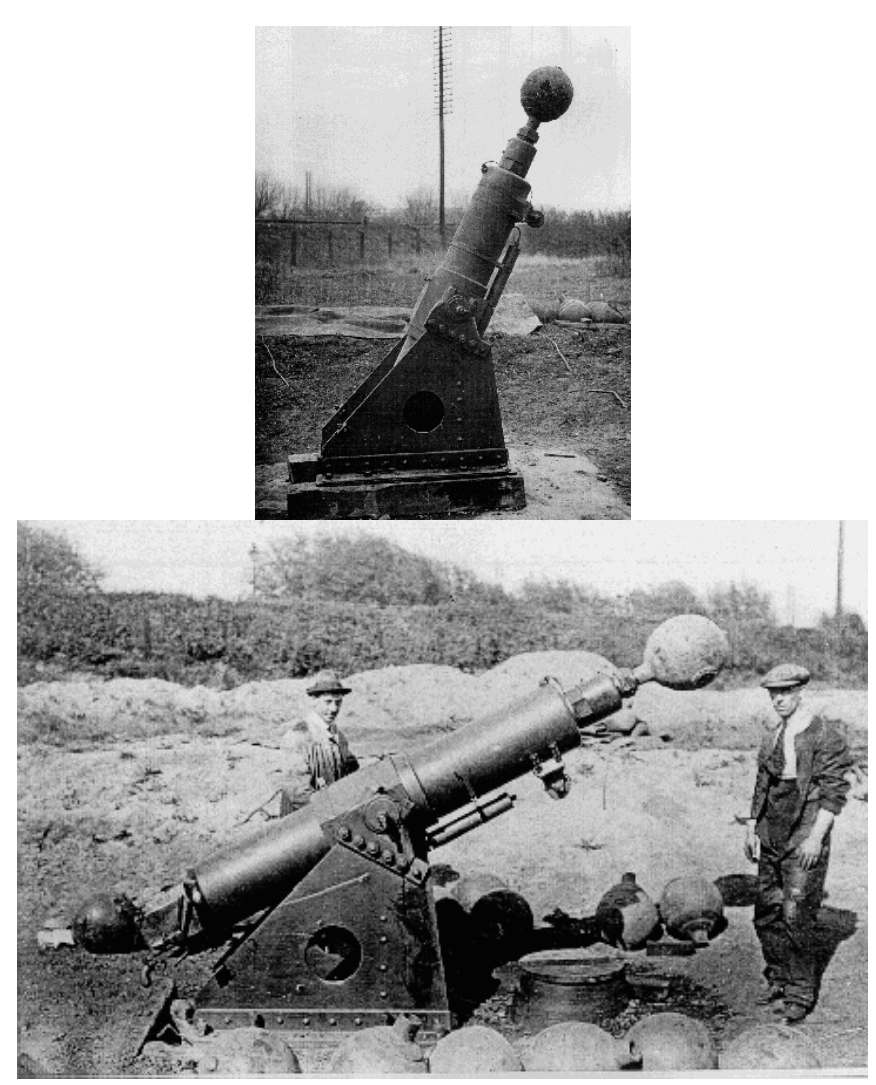

Fig. 13: Sonic guns

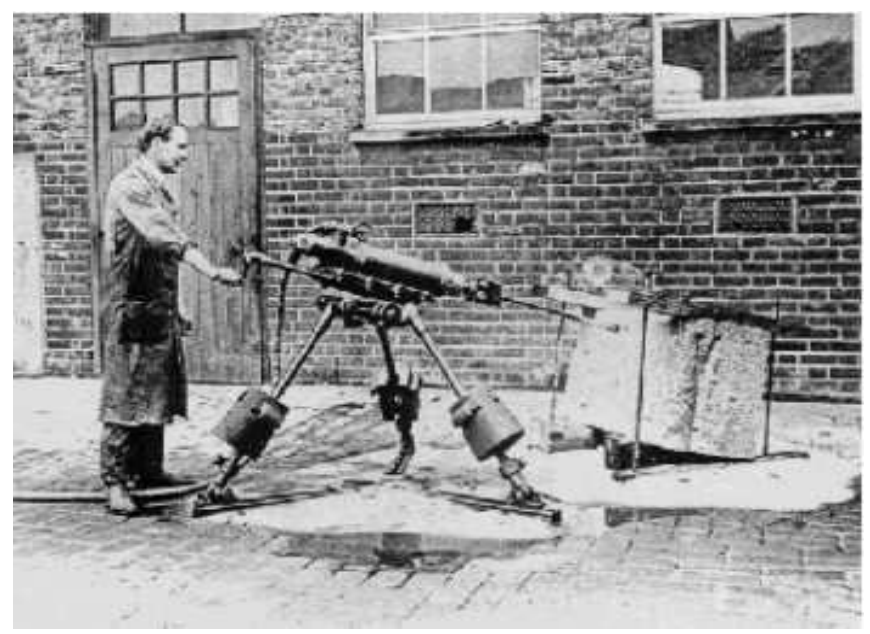

Fig. 14: The sonic hammer

Their advantages also to mechanical motors with reductions by mechanical transmission and to the motors and hydraulic transmissions, but especially in relation to the electric motors, is to achieve extremely large couples or couples variable in very wide beaches, which selfadjusting to instant demands, which can be maintained as long as they are needed, without heating, without extra effort, without noise or vibration, without shocks (thus without any breaks), without wear, no adjustments, no maintenance, or need for other interventions.

The sonic engines have the characteristic of adapting themselves automatically to the required load so that the primary engine (primary power source), a diesel engine, for example, can constantly work at constant speed, load and power, even if the consumer (the sonic engine, or sonic engines) varies torque and speed in a very wide range. 


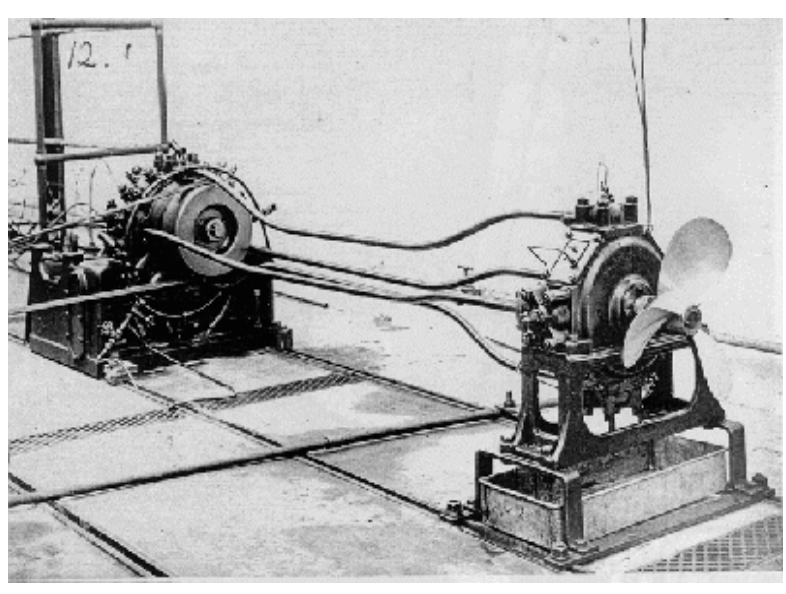

Fig. 15: The sonic transmission of marine vessels, which has the advantage of transmitting power through a single duct, without requiring two pipes for an installation

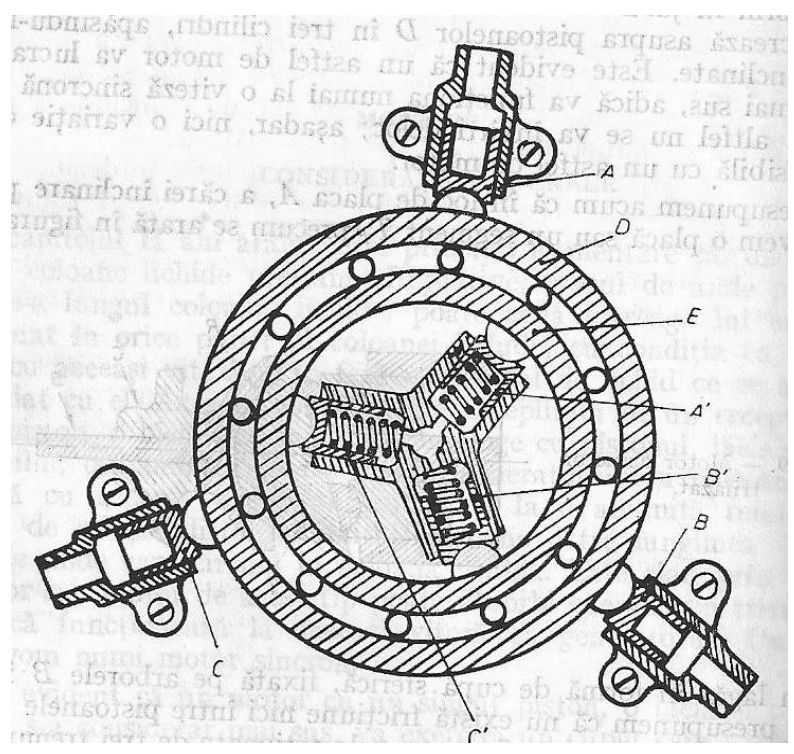

Fig. 16: A single, three-phase version of a sonic engine

Engines and synchronous sonar generators are similarly similar and their operation is reversible. The following figure shows a synchronous two-sided synchronous machine (Fig. 17).

The orifices a, b, c are provided for the connecting pipes between the generator and the receiver. These holes communicate with the cameras a1, b1, c1, each connected to three pistons $\mathrm{p} 1, \mathrm{p} 2, \mathrm{p} 3$, radially arranged. Pistons come in contact with an eccentric $d$ by means of a radial bearing. The eccentric is mounted on the spindle. The spaces communicating with the orifices a, b, c are filled with liquid and the pistons are eccentrically pushed by the spring. A fluid suitable to the described transmission system could be a mineral oil, but in principle, any fluid (liquid or gas) can be used.

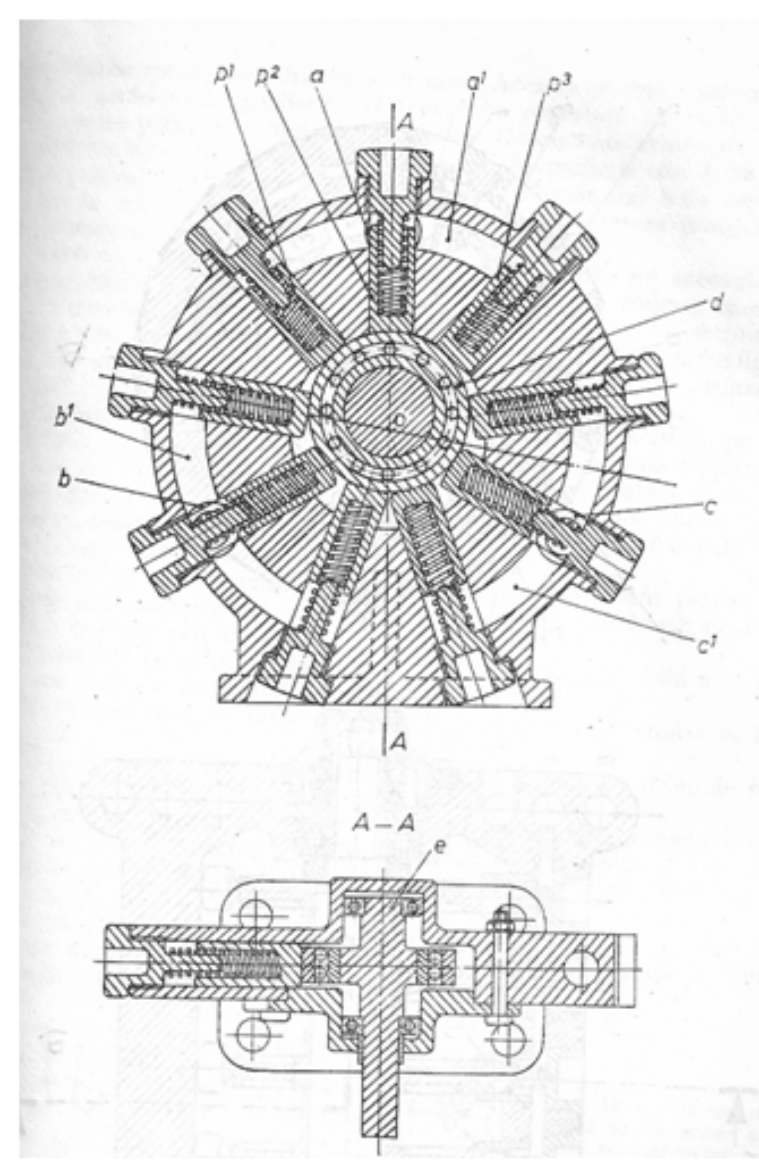

Fig. 17: A synchronous two-sided synchronous machine

The engine arrangement (design) in the figure provides for a three-piston displacement for a single phase. This achieves a more compact construction, lower pressures on the contact surface between the eccentric bearing and the pistons, greater displacement for one phase than the situation where a single piston would be used per phase.

The described system is analogous to the three-phase electric system. An important advantage over electrical transmissions is that it can be used economically including for very low rotation speeds.

For the described machine, one impulse (pressure) is produced at each revolution in each phase.

If the sonic engine and sonic generator have identical constructions, their speeds will be equal.

The operation of the sonic transmission is only possible under certain conditions described by George Constantinescu.

To build a sonic power transmission system with synchronous machines having different rotation speeds (for example, if the generator has to work at high and very high speeds, it would be good to at least have the sonic engine run at low speeds for a less wear and easier start), another constructive scheme (another design) must 
be chosen; such a sonic engine comprises three groups of pistons in cylinders, each group being connected by certain connections to three columns of liquid, which transmit the oscillations given by the three-phase generator. The rotor is modeled so that the pistons in contact with it describe a complete sinewave movement when rotating with a circle fraction. The rotor is modeled as a multiple cam (multiple cam followers with pauses between them) each sinusoidal cam profile having a complete period (Fig. 18).

The rotor $b$ (virtually a camshaft) has five multi-disc discs marked with each disc having five sinusoidal cam profiles, that is, each disc is practically not a cam but multiple cams.

The cachets are basically ball balls (not ball balls, even sphere balls) and have the role of a stick or piston, playing without play in the dice cylinders supported by the springs.

The stator piston (ball) will perform as many oscillations (strokes) as possible during a complete rotation of the rotor, as many sinusoidal profiles exist on multiple disc cams (for the engine in Fig. 5 oscillations).

The speed reduction ratio will be $1 / \mathrm{M}=1 / 5$.

If 20 special pistons are arranged at equal angles around the rotor to make it as light as possible (low inertia), then at each revolution each of the 20 pistons will produce 20 twin pulses as the magnitude of the sinusoid modulated on the rotor (Fig. 19).

Such a high-frequency sonic generator (Fig. 20) can easily reach 20-30 kHz.

With the high-frequency sonic generators of the Romanian scientist George Constantinescu, special tools for glass processing were made, vibrated molten metal could be vibrated, various medical applications were made, the sonic hammer was built, the ultrasonication of the batteries of vehicle fuel), an improved oil drilling and/or extraction facility was obtained, sonic injection of diesel engines or gasoline injections, sonic intake (sonic distribution on car engines), the thermal effect radiator) through thin pipes, etc.

The Fig. 20 will show a sonic volumetric pump (sonic volumetric pump).

The water is admitted through the lower valve 140 into the pump chamber and is passed through the exhaust valve 142 into an air cushion 143 from where it is discharged through the service pipe 144 .

A separate pipe 145 feeds the alternative pressure wand.

These determine the alternate displacement of the piston 147 , sustained by the springs 148 and 149 , permanently.

This movement causes the volume to change in the space between the valves.

When the volume in the pump chamber is maximum, a depression is created to open the valve 140 by allowing water in the pump chamber. The pressure between the pump chamber and the exterior of the fluid equals the valve closing. The volume in the pump chamber starts to decrease by greatly increasing the pressure in the pump chamber, shutting the fluid in the room valve even better and opening the fluid outlet valve in the pump chamber by pushing the valve together with the excess fluid from the pump chamber into the vessel with an airbag. The pressure equals, both valves close, the piston moves and the volume of the pump chamber increases, a new depression occurs and the cycle resumes.

Figure 21 shows a sonic riveting hammer. It is composed of housing 120 which has a handle 121 in which there is a drive lever 122 which, by means of an accelerator 123 , opens the valve 124 by admitting the pressurized fluid from the transmission line to the tool.

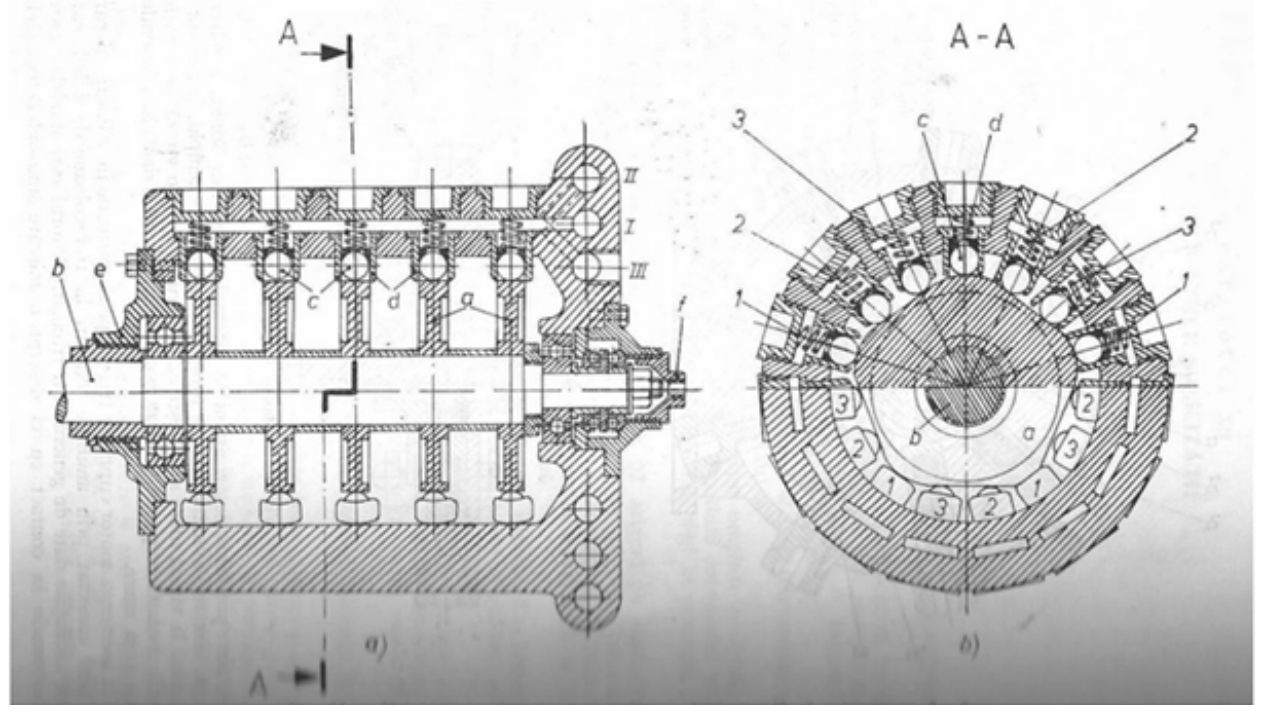

Fig. 18: A sonic power transmission system with synchronous machines having different rotation speeds 


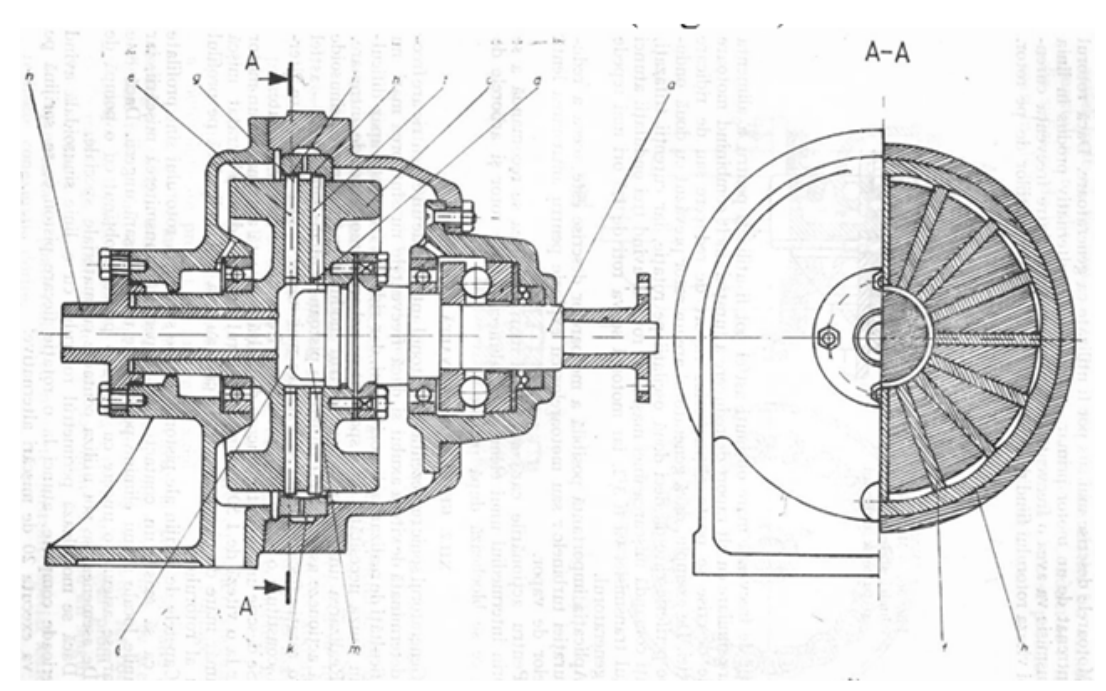

Fig. 19: Each of the 20 pistons will produce 20 twin pulses as the magnitude of the sinusoid modulated on the rotor

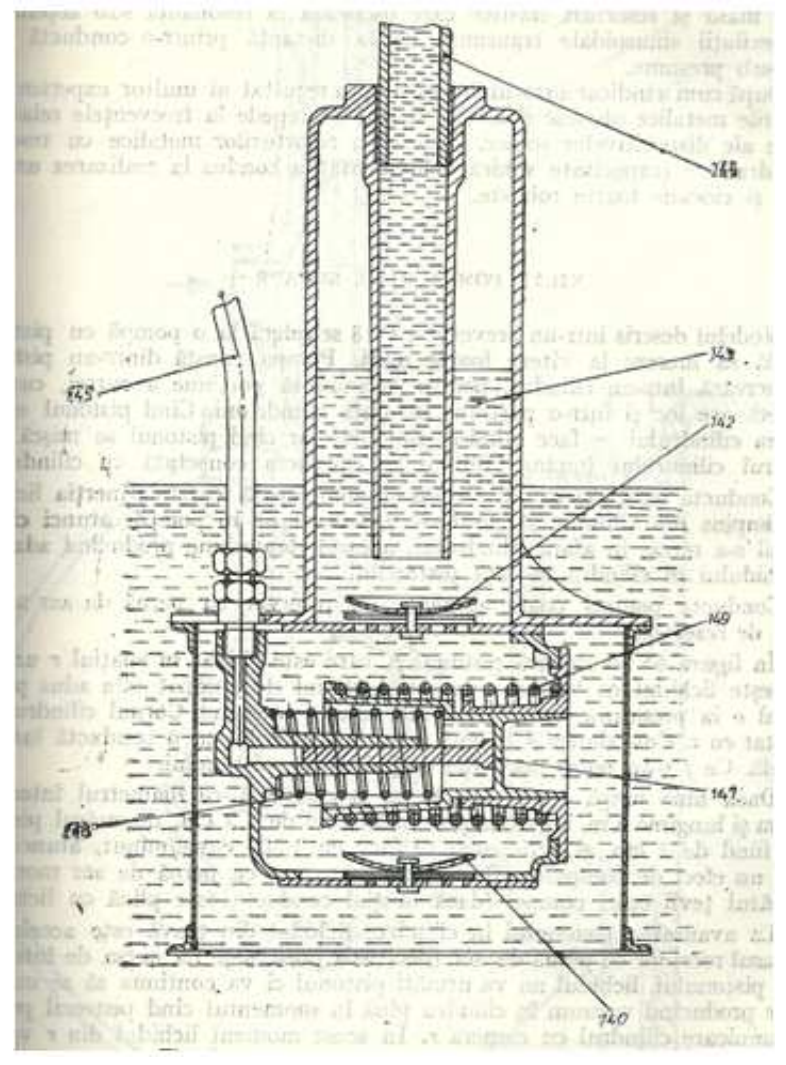

Fig. 20: A high-frequency sonic generator

The pressurized fluid presses the piston 125 violently, moving it extremely rapidly together with the impact piston (plunger). The striker piece is provided with flange 127 by means of which it is held in an intermediate position by the springs 128 and 129. The piece 126 transmits the stroke through the intermediate piece 130 .

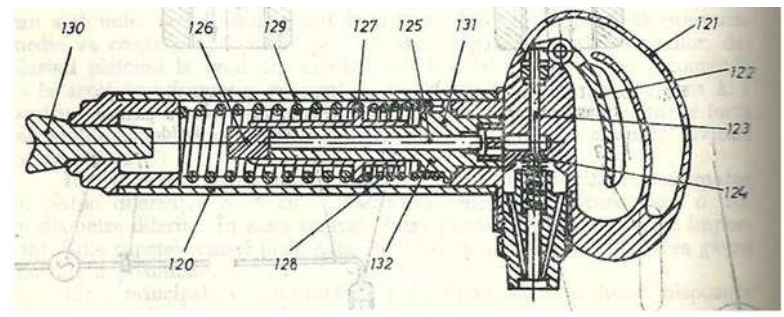

Fig. 21: A sonic riveting hammer

\section{Conclusion}

George Constantinescu demonstrated and perfected the effect of heating the fluids in the thin pipes based on the received sonic energy, in perfect similarity to the effect of Joule, by which the electric current heats at its passage the higher resistances (the thinner electric conductors). Interestingly, a variable (staged) pipe is heated only on smaller diameters when passing the sonic currents through it, the larger diameters remaining cold, the very small diameters warming up to red, for the same pipe with water (or a liquid) in it; the behavior is similar to that of electric conductors traversed by electric currents and not by pipes through which water passes, either cold or heated, when the entire pipe has the same temperature borrowed from the water passing it.

Because World War II was altogether different than the first, bringing Britain and the British Admiralty to the utmost alert, the story of the synchronized shooting no longer up to date, worked on all sorts of inventions capable of helping England. Generally, they remain secrets. But some have been narrated.

In a letter to the engineer Matei Marinescu (the son of his friend, doctor Gheorghe Marinescu) of April 14, 1958, George Constantinescu states, among other things, 
"I was delighted to find out from your letter (dated 21.02.1958) was elected as an honorary member of the Romanian Academy. Meanwhile, I have received news from Mr. Bazgan, who is one of the few who have shown interest in my Sonic work and who are sure to have contributed to the progress of drilling technology."

\section{Acknowledgment}

The work in Romanian was appreciated by the corresponding author's uncle, |Costin DAMIAN|, director of the Romanian Academy until 1986, when he died. One year before he died, Costin Damian asked to some Romanian academics to translate the work "Sonicitatea" from English to Romanian and published it in the maximum allowed circulation in the academy's publishing house, so that his work would not be lost because at that time there was only one copy and that one in English and the first printed issue was given to his favorite nephew (the corresponding author, at the request of which he had done all this last effort). On this occasion, the corresponding author wishes to be grateful to his uncle (postmortem).

\section{Author's Contributions}

All the authors contributed equally to prepare, develop and carry out this manuscript.

\section{Ethics}

This article is original. Authors declare that are not ethical issues that may arise after the publication of this manuscript.

\section{References}

Aversa, R., R.V.V. Petrescu, A. Apicella and F.I.T. Petrescu, 2017a. Nano-diamond hybrid materials for structural biomedical application. Am. J. Biochemistry Biotechnol.

Aversa, R., R.V. Petrescu, B. Akash, R.B. Bucinell and J.M. Corchado et al., 2017b. Kinematics and forces to a new model forging manipulator. Am. J. Applied Sci., 14: 60-80.

Aversa, R., R.V. Petrescu, A. Apicella, F.I.T. Petrescu and J.K. Calautit et al., 2017c. Something about the $\mathrm{V}$ engines design. Am. J. Applied Sci., 14: 34-52.

Aversa, R., D. Parcesepe, R.V.V. Petrescu, F. Berto and G. Chen et al., 2017d. Process ability of bulk metallic glasses. Am. J. Applied Sci., 14: 294-301.

Aversa, R., F.I.T. Petrescu, R.V. Petrescu and A. Apicella, 2016a. Biomimetic FEA bone modeling for customized hybrid biological prostheses development. Am. J. Applied Sci., 13: 1060-1067. DOI: 10.3844 /ajassp.2016.1060.1067
Aversa, R., D. Parcesepe, R.V. Petrescu, G. Chen and F.I.T. Petrescu et al., 2016b. Glassy amorphous metal injection molded induced morphological defects. Am. J. Applied Sci., 13: 1476-1482.

Aversa, R., R.V. Petrescu, F.I.T. Petrescu and A. Apicella, 2016c. Smart-factory: Optimization and process control of composite centrifuged pipes. Am. J. Applied Sci., 13: 1330-1341.

Aversa, R., F. Tamburrino, R.V. Petrescu, F.I.T. Petrescu and M. Artur et al., $2016 \mathrm{~d}$. Biomechanically inspired shape memory effect machines driven by muscle like acting NiTi alloys. Am. J. Applied Sci., 13: 1264-1271.

Mirsayar, M.M., V.A. Joneidi, R.V.V. Petrescu, F.I.T. Petrescu and F. Berto, 2017. Extended MTSN criterion for fracture analysis of soda lime glass. Eng. Fracture Mechanics, 178: 50-59.

DOI: 10.1016/j.engfracmech.2017.04.018

Petrescu, FIT. 2016 Valorificarea Traditiei Ingineresti Romanesti-I: Create Space Publisher, USA, ISBN-13 9781537177984, 19 Aug 2016.

Petrescu, F.I. and R.V. Petrescu, 2011 a. Memories about Flight. 1st Edn., CreateSpace, pp: 652.

Petrescu, F.I. and R.V. Petrescu, 2011b. Mechanical Systems, Serial and Parallel - Course (in romanian). 1st Edn., LULU Publisher, London, UK, pp: 124.

Petrescu, R.V. and F.I.T. Petrescu, 2012a. Northrop. Books on Demand. ISBN-13: 978-3848209323, pp: 142.

Petrescu, F.I. and R.V. Petrescu, 2012b. New Aircraft II. 1 st Edn., Books on Demand, pp: 138.

Petrescu, F.I. and R.V. Petrescu, 2012c MecatronicaSisteme Seriale si Paralele. 1st Edn., CreateSpace Independent, USA, ISBN-13: 978-1481138338, pp: 128.

Petrescu, F.I. and R.V. Petrescu, 2012d. Kinematics of the planar quadrilateral mechanism. Engevista, 14: 345-348.

Petrescu, R.V. and F.I. Petrescu, 2013a. Lockheed Martin. 1st Edn., CreateSpace, pp: 114.

Petrescu, R.V. and F.I. Petrescu, 2013b. Northrop. 1st Edn., CreateSpace, pp: 96.

Petrescu, R.V. and F.I. Petrescu, 2013c. The Aviation History or New Aircraft I Color. 1st Edn., CreateSpace, pp: 292.

Petrescu, F.I. and R.V. Petrescu, 2013d. Cinematics of the 3R dyad. Engevista, 15: 118-124.

Petrescu, F.I. and R.V. Petrescu, 2016a. Parallel moving mechanical systems kinematics. ENGE-VISTA, 18: 455-491.

Petrescu, F.I. and R.V. Petrescu, 2016b. Direct and inverse kinematics to the anthropomorphic robots. ENGEVISTA, 18: 109-124.

Petrescu, F.I. and R.V. Petrescu, 2016c. Dynamic cinematic to a structure 2R. Revista Geintec-Gestao Inovacao E Tecnol., 6: 3143-3154.

Petrescu, F.I.T. and J.K. Calautit, 2016a. About Nano fusion and dynamic fusion. Am. J. Applied Sci., 13: 261-266. 
Petrescu, F.I. and J.K. Calautit, 2016b. About the light dimensions. Am. J. Applied Sci., 13:321-325. DOI: 10.3844 /ajassp.2016.321.325

Petrescu, F.I.T., 2009. New aircraft. Proceedings of the 3rd International Conference on Computational Mechanics, Oct. 29-30, Brasov, Romania.

Petrescu, F.I.T., 2012a. Cold Nuclear Fusion. 1st Edn., Create Space, USA, pp: 80.

Petrescu, F.I.T., 2012b. Particle Annihilation-A source of renewable energy? http://blog.hasslberger.com/technology/

Petrescu, F.I.T., 2012c. Particle annihilation-a source of renewable energy? Infinite Energy.

Petrescu, R.V.V., R. Aversa, A. Apicella, F. Berto and S. Li et al., 2016a Ecosphere protection through green energy. Am. J. Applied Sci., 13: 1027-1032.

Petrescu, F.I.T., A. Apicella, R.V.V. Petrescu, S.P. Kozaitis and R.B. Bucinell et al., 2016 b. Environmental protection through nuclear energy. Am. J. Applied Sci., 13:941-946.

Petrescu, R.V., R. Aversa, B. Akash, R. Bucinell and J. Corchado et al., 2017a. Modern propulsions for aerospace-a review. J. Aircraft Spacecraft Technol., 1: $1-8$.

Petrescu, R.V., R. Aversa, B. Akash, R. Bucinell and J. Corchado et al., 2017b. Modern propulsions for aerospace-part II. J. Aircraft Spacecraft Technol., 1: 9-17.

Petrescu, R.V., R. Aversa, B. Akash, R. Bucinell and J. Corchado et al., 2017c. History of aviation-a short review. J. Aircraft Spacecraft Technol., 1: 30-49.

Petrescu, R.V., R. Aversa, B. Akash, R. Bucinell and J. Corchado et al., 2017d. Lockheed martin-a short review. J. Aircraft Spacecraft Technol., 1: 50-68.

Petrescu, R.V., R. Aversa, B. Akash, J. Corchado and F. Berto et al., 2017e. Our Universe. J. Aircraft Spacecraft Technol., 1: 69-79.

Petrescu, R.V., R. Aversa, B. Akash, J. Corchado and F. Berto et al., 2017f. What is a UFO? J. Aircraft Spacecraft Technol., 1: 80-90.

Petrescu, R.V., R. Aversa, B. Akash, J. Corchado and F. Berto et al., 2017g. About bell helicopter FCX-001 concept aircraft-a short review. J. Aircraft Spacecraft Technol., 1: 91-96.
Petrescu, R.V., R. Aversa, B. Akash, J. Corchado and F. Berto et al., 2017h. Home at airbus. J. Aircraft Spacecraft Technol., 1: 97-118.

Petrescu, R.V., R. Aversa, B. Akash, J. Corchado and F. Berto et al., 2017i. Airlander. J. Aircraft Spacecraft Technol., 1: 119-148.

Petrescu, R.V., R. Aversa, B. Akash, J. Corchado and F. Berto et al., 2017j. When Boeing is dreaming - a review. J. Aircraft Spacecraft Technol., 1: 149-161.

Petrescu, R.V., R. Aversa, B. Akash, J. Corchado and F. Berto et al., 2017k. About Northrop Grumman. J. Aircraft Spacecraft Technol., 1: 162-185.

Petrescu, R.V., R. Aversa, B. Akash, J. Corchado and F. Berto et al., 20171. Some special aircraft. J. Aircraft Spacecraft Technol., 1: 186-203.

Petrescu, R.V., R. Aversa, B. Akash, J. Corchado and F. Berto et al., 2017m. About helicopters. J. Aircraft Spacecraft Technol., 1: 204-223.

Petrescu, R.V., R. Aversa, B. Akash, F. Berto and A. Apicella et al., 2017n. The modern flight. J. Aircraft Spacecraft Technol.

Petrescu, R.V., R. Aversa, B. Akash, F. Berto and A. Apicella et al., 2017o. Sustainable energy for aerospace vessels. J. Aircraft Spacecraft Technol.

Petrescu, R.V., R. Aversa, B. Akash, F. Berto and A. Apicella et al., 2017p. Unmanned helicopters. J. Aircraft Spacecraft Technol.

Petrescu, R.V., R. Aversa, B. Akash, F. Berto and A. Apicella et al., 2017q. Project HARP. J. Aircraft Spacecraft Technol.

\section{Source of Figures:}

Fig. 1:

https://www.google.ro/search?q=George $+($ Gogu $)+$ Const antinescu + photos \&client $=$ firefox-

$\mathrm{b} \& \mathrm{dcr}=0 \& \mathrm{tbm}=\mathrm{isch} \&$ source $=\mathrm{iu} \& \mathrm{ictx}=1 \&$ fir $=\mathrm{KMiW} 70 \mathrm{f}$ A-

V0BuM\%253A\%252CfEF7Q1LuQnsWlM\%252C \&usg $=2 \mathrm{TjWW7mjUkUSYMiYrY1-}$

Bur4WKA\%3D\&sa=X\&ved=0ahUKEwimvJrGj9jXAh

VI6xoKHSosDXYQ9QEINjAG\#imgrc=KMiW70fA-

V0BuM:

Fig. 2-21: Petrescu, 2016. 